\title{
PROBABILISTIC PREDICTING IN SPEECH IN DISTRESS AND AT THE NEUROTIC DISORDERS
}

\author{
Marina M. Solobutina \\ Department of General and Applied Psychology, \\ Kazan Federal University, Kremlevskaya st., 18, Kazan, 420000, Russian Federation
}

Received 2014-05-26; Revised 2014-06-17; Accepted 2014-06-25

\begin{abstract}
The present article provides the results obtained in course of the empirical investigation on the probabilistic predicting in the speech activity. The aim of the research was to show the nature of interrelation between the predicting abilities in the speech activity and severity of distress at the neurotic disorders. In course of the research the following hypotheses were developed: (1) Predicting abilities in the speech activity correlate to the severity of distress at the neurotic disorders; (2) degree of speech predicting disruption depends upon the neurotic disorder's severity. The results of the research have allowed to specify that the human body's emotional and physiological tension in response to strong and long-lasting stress factor is accompanied by impairment in predicting abilities in the speech activity. The disruption of the probabilistic predicting in the patients suffering from neurotic disorders complicates anticipation of the forthcoming speech situation and causes the disruption in predicting of the speech message's essence. It has been established that the neurotic disorders are followed by the disruption in the speech activity. However, the degree of disruptions depends not only upon the distress severity, but also the psychopathological symptoms' manifestation rate and disorder's intensity. The experience of negative stress consequences curtails the predicting abilities in the speech activity both for the mentally healthy ones and suffering from neuroses, though, not equally: The disruptions in verbal predicting are more sufficient at the neurotic disorders. The actualization peculiarities of the ideolexicon's probabilistic structure are greatly changed under the influence of the morbid process development. The patients with comparatively non-profound neurotic disorders are able to perform predicting in the speech activity, whereas the predicting incompetence is stated concerning the speech activity at the intensification of the disorder's clinical evidences. It was concluded that the disruption of predicting the semantic relations in the verbal message in the persons suffering from the greatly intensive distress causes anxiety in course of communication together with avoiding of psychotraumatic speech situations and that, in its turn, creates obstacles in communication and shapes readiness for neurotic interpretation of the reality.
\end{abstract}

Keywords: Probabilistic Predicting, Speech Activity, Distress, Neurotic Disorders

\section{INTRODUCTION}

The researches revealing the peculiarities of human adaptation under current conditions and the causes of competence disorders are important in the modern psychology. It has already been established that actualization of difficult mental states as the result of the external negative impact on mental and physiological function of the organism is one among the causes of the irrational, abnormal behavior. The stress occurrence is accompanied by the changes in intensity of plenty various processes both in human body and mind-either increasing, or decreasing (Shcherbatykh, 2000). If the external impact is of sufficient power that exceeds the adaptive abilities of the human organism and so, there is an inability of mobilization in the stressful situation, the primary stress can transform into the destructive, damaging form-distress (Selye, 2004). The mental 
tension caused by a severe stress tends to cause changes in the whole mental sphere of a human being and that, in turn, prevents from successful and well-timed solving of the stressful situation (McWilliams, 2011). The state of distress is accompanied by the affective, physiological manifestations and cognitive imbalance. The disorders in basic properties of the intellect are a consequence of the stress development, on the one hand and tend aberrations in the interpretation of events and abnormal behavior, also prevent from successful way out from the stressful psycho-traumatic situation, on the other hand (Nozdrachev and Shcherbatykh, 2000).

The generally known psychological theories prove that the predicting ability is one of the conditions of successful adaptation of an individual and efficient solution of the stressful situation (Nichiporenko and Mendelevich, 2006). Predicting is an ability to reflect tendencies of the environment within the structure of the past experience, to create the behavioral strategies, while anticipating the sequence of events, forecast the development of situations and one's own responses to them (Lomov and Surkov, 1980; Sergienko, 1997). Due to high development of the predicting abilities at the verbal-cogitative and communicative levels, the human being is able to understand and estimate the behavior of surrounding persons, anticipate utterances of other communicants and be ready for multi-probabilistic response, while choosing the best-efficient way of interaction with them (Regush, 2003).

Impairment in predicting abilities determines the social maladjustment, whereas the person's abilities to probabilistic predicting are among the factors of the healthy, stress resistant personality who is able to overcome life difficulties and interact with others efficiently. The study of the probabilistic predicting in the speech allows to estimate indirectly the ability to anticipate events and forecast the development of a verbal situation. However, the human speech predicting under the negative influence of the stress remains unexplored yet. The aberration in the probabilistic structure of the past experience at distress could complicate the anticipation of the forthcoming verbal situation and cause the disruption in the speech predicting at the level of semantic hypotheses, what could become a cause for the obstacles in communication and form the readiness for abnormal interpretation of the reality.

\section{MATERIALS AND METHOD}

The aim of the present research was to explore the peculiarities of predicting in course of semantic perception of speech and actualization of verbal connections depending on the distress severity, both normally and at the neurotic disorders. The overall volume of the sample was 270 persons, both male and female, at the age of 25-50. The exploration was based upon the study and comparative analysis of the peculiarities of the probabilistic predicting in speech at the semantic level in three groups of the surveyed ones:

- The healthy persons, never experiencing any sufficient stress at the moment of the research (100 persons)

- The healthy persons in significant distress (80 persons)

- The day patients suffering from various neurotic disorders being treated at the Kazan Republican Mental Health Facility (90 persons)

Clinical group forming among the patients suffering from the neurotic disorders has been undertaken on purpose of the best fundamental understanding of the phenomenon of predicting in the speech activity. The genesis of neurosis is the result of the personality's incompetence to anticipate the sequence of events and one's own behavior in the situations of frustration-the reason for this is the predicting incompetence of a "prospective neurotic person". This assumed that the comparison of the diagnostic results of the verbal predicting both in health and disease would allow to detect the degree of probable disruptions of predicting in the healthy ones experiencing the stress destructive consequences.

The method of filling in the phrasal gaps was employed as the research tool providing estimation of the predicting abilities at the semantic perception of speech. The Shcherbatykh (2000) Stress Manifestation Integral Assessment Method and SCL-90-R Questionnaire were applied for the distress severity detection in the surveyed persons.

\section{RESULTS}

The results of the stress manifestation exploration obtained by means of Yu.V. Shcherbatykh's method allowed to assume that the majority of the healthy surveyed from the first group have never experienced any sufficient stress $(65 \%)$, while the others suffered from moderate stress compensated by the enough inner resources for its surmounting. The group of the healthy ones who underwent psychological difficulties at the moment of the test demonstrated sufficiently expressed 
tension of both emotional and physiological systems of organism together with stress negative consequences connected to the inability to resist to the stress factor's impact and also adaptive resources depletion in a personality. The rate of persons with vividly expressed distress prevailed in the group of the patients suffering from the neurotic disorders.

The testing with the SCL-90-R Questionnaire recognized that both GSI and PDSI parameters demonstrating the general disorder severity and existent distress indices exceeded their standard values in the neurotic patients. The psychopathology caused by the psycho-traumatic situation was peculiar to all examined patients suffering from neuroses. The results are in Table 1. That was expressed by extremely high quantitative values for all sets of symptoms and caused by sufficiently wide range of symptoms (PST $c p=58$ ). The stress factor's negative impact tension indicator exceeded the standard value in the second group of the healthy surveyed ones as well, however the distress severity degree was less, while the complaints range stayed within the closer limits, as compared to the neurotic patients. The fact of any neurotic disorder for these surveyed persons was excluded, whereas both the nature and amount of their complaints never met the clinical criteria for the disorders included in ICD-10, Section F-4.

The " $S$-standard rate" revealing the ratio of explored parameter intensity in the particular examined human being to the maximum possible intensity of this very parameter in general was applied for the efficiency determining as for the probabilistic predicting of the semantic connections. In the present research dedicated to study of the verbal prediction at the semantic level $91 \%$ of the healthy surveyed ones demonstrated $S \geq 0.84$ (Table 1). This very value of $S-\geq 0.84$-was selected as the limit of $S$ value range equal to "norm". $72.2 \%$ of the surveyed patients demonstrated $S$ value beyond the "normal" range. It means their results gave evidence on speech predicting disruptions at the semantic level. The predicting mistakes were peculiar to those latter group of the surveyed persons. The tested ones in the control group normally fulfilled the task appropriately. In the group of healthy ones experiencing the vivid distress nearly half of the surveyed persons showed the results like to the first group $(41.3 \%)$, whereas the rest of the group found it difficult to fulfill the task. Only $44.4 \%$ of the group of neurotic patients showed high language proficiency, thinking criticism and flexibility and also proper vocabulary units handling based upon their semantical and grammatical combination (Group I-81\%, Group II68.7\%). Thinking rigidity, associative inefficiency, retardation and discontinuity of verbal-cogitative processes were typical for $55.6 \%$ of the tested persons. Concerning the surveyed experiencing distress, $32.5 \%$ of the healthy surveyed ones and $58.9 \%$ of the neurotic patients experienced emotional tension in the situations of communications and found it difficult to control their own verbal behavior and also establish new contacts.

Table 1. Results of distress manifestations integral assessment

\begin{tabular}{|c|c|c|c|c|c|c|}
\hline \multirow[b]{2}{*}{ Parameters } & \multirow[b]{2}{*}{$\begin{array}{l}\text { Mean values } \\
\text { I. Healthy }\end{array}$} & \multicolumn{5}{|c|}{ Compared Groups $\left(t_{\text {empirical }}\right)$} \\
\hline & & $\begin{array}{l}\text { II. Healthy } \\
\text { Experiencing distress }\end{array}$ & $\begin{array}{l}\text { III. Neurotic } \\
\text { Patients }\end{array}$ & $\mathrm{I}-\mathrm{II}$ & I-III & II-III \\
\hline$S$ standard rate & 0.85 & 0.66 & 0.57 & 1.93 & 3.80 & 2.70 \\
\hline$D$ distress severity & 7.50 & 38.00 & 56.80 & 18.30 & 31.50 & 7.50 \\
\hline Distress intellectual symptoms & 2.30 & 7.40 & 10.50 & 5.04 & 12.01 & 3.40 \\
\hline Distress behavioral symptoms & 1.20 & 5.90 & 9.00 & 6.10 & 15.30 & 4.30 \\
\hline Distress emotional symptoms & 2.80 & 11.30 & 15.90 & 4.70 & 11.90 & 2.80 \\
\hline Distress physiological symptoms & 1.50 & 12.80 & 21.70 & 2.40 & 16.20 & 8.60 \\
\hline GSI general disorder severity index & 0.30 & 0.70 & 1.60 & 1.85 & 5.80 & 2.50 \\
\hline PDSI existent symptomatic distress index & 0.81 & 1.50 & 2.14 & 2.01 & 6.79 & 3.40 \\
\hline Somatization disorder & 0.35 & 0.90 & 1.89 & 2.30 & 3.08 & 2.60 \\
\hline Obsessive-compulsive disorders & 0.15 & 0.50 & 1.81 & 1.76 & 5.72 & 2.90 \\
\hline Interpersonal sensitivity & 0.40 & 1.10 & 1.54 & 3.45 & 4.20 & 3.70 \\
\hline Depression & 0.62 & 0.89 & 1.85 & 0.71 & 3.30 & 3.00 \\
\hline Anxiety & 0.33 & 1.00 & 2.06 & 1.90 & 6.34 & 4.90 \\
\hline Hostility & 0.55 & 0.80 & 1.35 & 1.12 & 3.91 & 2.40 \\
\hline Phobic anxiety & 0.05 & 0.20 & 1.25 & 0.47 & 4.48 & 3.95 \\
\hline Paranoid symptoms & 0.18 & 0.50 & 1.33 & 0.80 & 4.01 & 2.70 \\
\hline Psychoticism & 0.00 & 0.01 & 1.60 & 0.00 & 2.25 & 2.10 \\
\hline
\end{tabular}


The assessment of the distress symptomatology and severity impact on the predicting in course of speech sensual perception has detected the inverse interrelation between these parameters in the groups of the healthy experiencing distress and neurotic patients $(r S$; GSI (II) $=$ $-0.31^{* * *} ; r S ; G S I$ (III) $\left.=-0.56^{* * * *}\right)$. Values of $\mathrm{D}$ and PDSI indicators in the healthy control group relate to the standard rates $\left(r(S ; D)=-0.76^{* * * *}\right.$ and $r(S ; P D S I)=-$ $0.48 * * * *)$ and so, prove the absence of the negative stressful nature. The peculiarities of the revealed interrelation in the group of the healthy experiencing distress point to the fact of impairment in the predicting abilities in the speech activity at the verbal connections actualization. While experiencing distress, the healthy surveyed ones make predicting failures in their speech activity in course of the verbal connections actualization.

\section{DISCUSSION}

The analysis of the hypotheses developed in course of the present research during the filling in phrasal gaps stated that the healthy ones experiencing various degrees of distress and the neurotic patients gave almost half as large again variants of answers than the healthy surveyed persons. The answers of the former ones were not able for greater variety. However, the neurotic patients' responses were marked by the decrease in number of highly probable, popular responses and increase in the hardly probable ones. The total amount of the highly probable answers was lower both for the healthy ones experiencing distress and neurotic patients. The healthy tested persons established the highest possible amount of probable semantic connections between lexemes during semantic perception of speech.

This result correlates to the generally accepted models of predicting in the speech activity. The general psychological tendencies of predicting in the speech activity upon condition of knowing the purport of the utterance are following: In the situation of communication the human being uses that combination of lexemes, which was the most frequent in his past experience and so, coincides to the "linguistic probability" of these lexemes combination (Zimnyaya, 2001). Predicting at the semantic level is accomplished basing upon looking ahead the thought of the speaker, establishing and particular implementation of the semantic connections (Regush, 2003).

Due to the detected predicting inability in the speech activity concerning those surveyed who were experiencing the stress destructive consequences, it became reasonable to examine the influence of the observed disruptions in verbal predicting upon the conversation practice of the tested persons. The disorders of the speech experience's probabilistic structure in distress reflected on the nature of the individual's interpersonal interaction. There is a whole range of the explorations denoting the necessity of researches dedicated to the specific individual-psychological peculiarities at personality disorders (Westen and Müderrisoğlu, 2006; Evraire and Dozois, 2011). The persons suffering from the neurotic disorders demonstrate distinctive aspects in the predicting activity at various degree of religionism (Frolova, 2014), whereas the nature of the interrelations with other people changes in case of the panic disorders (Lutz et al., 2014). The examination of both the healthy surveyed experiencing distress and neurotic patients within the present research allowed to detect the interpersonal sensitivity and raise of anxiety in course of the communicative act.

High achievement in the communicative competence development presupposes the contextual adaptability, also both verbal and non-verbal behavioral means fluency, proper and rapid skills of orientation in numerous and various communicative situations, mastering of efficient communicative technique (Nichiporenko and Mendelevich, 2006). The contemporary researches prove that the efficiency of communication depends on proper understanding and predicting of the interlocutor's speech utterances (Akhmetzyanova, 2014). The results of the present research have proven that the disruption in the probabilistic predicting at the verbal-cogitative and communicative levels could lead to frequent failures in the assessment of the surrounding persons' behavior and so, inefficient interaction with them. The speech situations could grow into psycho-traumatic ones (Sylvers et al., 2011). The tension of both emotional and physiological systems of the human organism as a response to strong and long-lasting stress factor is accompanied by impairment in predicting abilities in the speech activity, while the disorders' severity depends on the distress manifestation rate.

\section{CONCLUSION}

The research results allow to assert that the excessive power and prolongation of the stress factors causing the transition of the primary stress into distress determine the peculiarity of the predicting abilities in the speech activity. While attempting to predict the forthcoming speech situation as for the healthy ones suffering from 
the vivid distress and neurotic patients, a great amount of hypothetical answers often appears. At that, the proper variants of the forecast blend into the plenty of hardly probable forecasts. At the semantic perception of speech these very surveyed ones prefer either hardly probable, or improper answers. It has been established that the neurotic disorders are accompanied by the disruption in the predicting in the speech activity, but the disruptions severity depends not only upon the distress intensity, but also the manifestation rate of the psychopathological symptomatology and disruption severity.

The present article submits the data on the nature of the distress manifestation rate's influence upon the predicting abilities in the speech activity both normally and at the neurotic disorders. The prospects for future researches reside in the exploration of the probabilistic predicting in the speech activity at the various clinical forms of the neurotic disorders. Perhaps, the analysis of prediction in speech with due regard to various sets of symptoms will allow to reveal the specific nature of this very mechanism depending on the clinical performance of the disease. Furthermore, the disruptions in the speech prediction could be observed at other mental disorders, what, of course, is of both theoretical and practical interest.

\section{ACKNOWLEDGEMENT}

The author acknowledges insightful comments from Mendelevich V.D., Professor, Head of the Department of Medical and General Psychology of Kazan State Medical University and Frolova A.V., Head of the Department of General and Applied Psychology of Kazan Federal University.

\section{REFERENCES}

Akhmetzyanova, A.I., 2014. Spatial and temporal elements of anticipation consistency of children with general speech retardation. Am. J. Applied Sci., 11: 1031-1035. DOI: 10.3844/ajassp.2014.1031.1035

Evraire, L.E. and D.J.A. Dozois, 2011. An integrative model of excessive reassurance seeking and negative feedback seeking in the development and maintenance of depression. Clin. Psychol. Rev., 31: 1291-1303. DOI: 10.1016/j.cpr.2011.07.014

Frolova, A.V., 2014. Peculiarities of predictive activity of persons who have neurotic disorders with various intensity of religious activity. World Applied Sci. J., 29: 1586-1590.
Lutz, W., S.G. Hofmann, J. Rubel, J.F. Boswell and M.K. Shear et al., 2014. Patterns of early change and their relationship to outcome and early treatment termination in patients with panic disorder. J. Consult. Clin. Psychol., 8: 287-297. DOI: 10.1037/a0035535

Lomov, B.F. and E.N. Surkov, 1980. Anticipation Within Activity. 1st Edn., Nauka, Moscow, pp: 278.

McWilliams, N., 2011. Psychoanalytic Diagnosis. 2nd Edn., Guilford Press, ISBN-10: 160918498X, pp: 426.

Nozdrachev, A.D. and Y.V. Shcherbatykh, 2000. Modern methods of functional studies of the autonomic nervous system. Human Physiol., 27: 732-737. DOI: 10.1023/A:1012993430373

Nichiporenko, N.P. and V.D. Mendelevich, 2006. Predictive capabilities phenomenon as a subject of the psychological researches. Psychological Journal, 5: 50-59.

Regush, L.A., 2003. Psychology of Prediction: Success in Foreknowledge. 1st Edn., Rech, Saint Petersburg, pp: 352.

Shcherbatykh, Y.V., 2000. Self-regulation of autonomic homeostasis in emotional stress. Human Physiol., 26: 641-642. DOI: 10.1007/BF02760382

Sylvers, P., S.O. Lilienfeld and J.L. LaPrairie, 2011. Differences between trait fear and trait anxiety: Implications for psychopathology. Clin. Psychol. Rev., 31: 122-137. DOI: 10.1016/j.cpr.2010.08.004

Selye, G., 2004. What is a stress? In Psychology of States. Anthology. Eds., Prokhorov, A.O. Moscow, Saint Petersburg: PER SE, Rech, pp: 298-302.

Sergienko, E.A., 1997. Anticipation as a principle of the mental development. Moscow: Rech, pp: 198.

Westen, D. and S. Müderrisoğlu, 2006. Clinical assessment of pathological personality traits. Am. J. Psychiatry, 163: 1285-1287. DOI: 10.1176/appi.ajp.163.7.1285

Zimnyaya, I.A., 2001. Linguistic psychology of speech activity. Moscow, Rech. pp: 432. 